Journal of

Ecology 1999, 87, 436-449

\title{
Variation in the effects of vegetation and litter on recruitment across productivity gradients
}

\author{
KATHARINE NASH SUDING and DEBORAH E. GOLDBERG \\ Department of Biology, University of Michigan, Ann Arbor MI 48109, USA
}

\begin{abstract}
Summary
1 We tested predictions about how the effect of vegetation and litter on seedling establishment varies among sites and herbaceous community types (sand barrens, prairies, fens). For both vegetation and litter, we also separated direct interactions from indirect interactions and interaction modifications along the gradient.

2 Although the intensity of the effects varied across sites, the direct effects of vegetation or litter alone were consistently facilitative along the productivity gradient. Predominance of facilitative effects may be due to the focus on the seedling establishment phase.

3 However, inclusion of indirect interactions and interaction modifications caused the net effects of both vegetation and litter to become largely negative. While one layer of biomass may be advantageous to ameliorate some moisture stress, the addition of another layer may be disadvantageous if this layer limits light proportionally more than it relieves moisture stress.

4 One exception to this pattern occurred at high productivity when the net effect of vegetation, even in the presence of litter, remained facilitative. The net effect of vegetation was competitive at low productivity and grew increasingly facilitative with productivity. Thus, indirect effects of litter may alter interaction patterns across this gradient.
\end{abstract}

Keywords: community response, competitive intensity, environmental gradients, facilitation, indirect interactions, interference, productivity

Journal of Ecology (1999) 87, 436-449

\section{Introduction}

Recruitment is often the critical stage for the maintenance of plant populations, and can thus influence their distribution and abundance (Harper 1977; Fenner 1985). While recruitment is frequently limited by interference from neighbouring adults (Goldberg 1987b; Bertness \& Yeh 1994), there are situations where adults may facilitate recruitment (Callaway \& Walker 1997). It is therefore important to understand what influences the balance between the negative and positive interactions with neighbouring plants.

Most hypotheses concerning patterns in the net magnitude of these interactions have specifically concerned the influence of productivity and/or the suitability of environmental conditions. For example, although competition may predominate at all productivity levels, its intensity may be low in unpro-

Correspondence: Katharine Nash Suding (fax 734647 0884; e-mailktnash@umich.edu). ductive environments due to harsh abiotic conditions, and increase with productivity due to greater amounts of neighbour biomass and frequency of size-asymmetric interactions (Grime 1979; Huston 1979; Thompson \& Grime 1988; Keddy 1989; Wisheu \& Keddy 1992; Fig. 1a, number 1). Alternatively, competitive intensity may be constant with respect to productivity, although the limiting resources may shift from below-ground resources (e.g. nutrients and water) to light as productivity increases (Newman 1973; Grubb 1985; Tilman 1988; Fig. 1a, number 2). Bertness \& Callaway (1994) suggest another alternative: interactions are not necessarily competitive along the entire productivity gradient. They predict that in areas with harsh edaphic conditions, vegetation will facilitate recruitment, but in physically benign areas competitive interactions will prevail (Fig. 1a, number 3).

The available empirical data that can be used to test these predictions have produced conflicting results to date; different studies support each of the three 

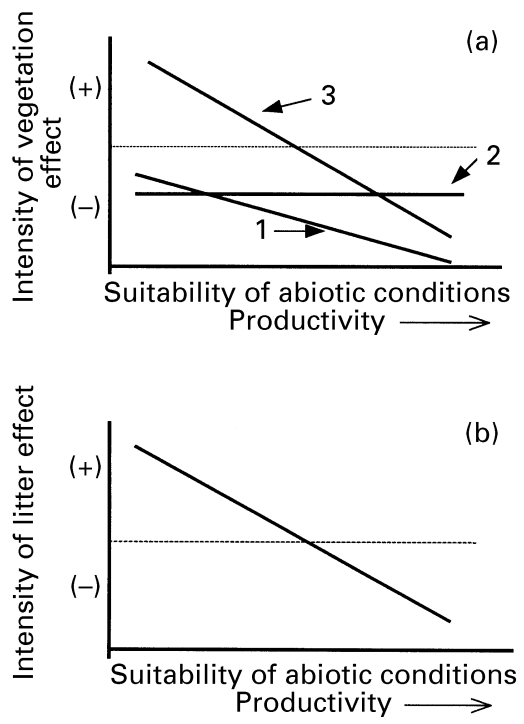

Fig. 1 Predictions about the effects of vegetation (a) and litter (b) across environmental gradients (see the text). The dotted line in each graph indicates zero effect; above that the effect is facilitative, below the effect is competitive. Three predictions are depicted for the effect of vegetation (labelled 13): (1) Grime (1979) predicts that competitive intensity will increase as productivity increases; (2) Tilman (1988) predicts that competitive intensity will remain constant along a productivity gradient; and (3) Bertness \& Callaway (1994) predict that the effect of vegetation will be facilitative under harsh abiotic conditions but will grow more competitive as the environment becomes more benign. Bertness \& Calloway (1994) also predict that facilitation will increase with increasing productivity due to increased consumer pressure, a relationship we do not depict here. For the effect of litter (b), Carson \& Peterson (1990) hypothesize that litter will negatively affect recruitment under productive conditions, but facilitate recruitment in more unproductive areas.

predictions (Gurevitch 1986; Wilson \& Tilman 1991; Wilson 1993; Kadmon 1995; Twolan-Strutt \& Keddy 1996; Goldberg et al. 1999). Although some of this conflict may be due to the environmental gradient, community type, or life-stage studied, we suggest that another crucial factor has been largely overlooked. Conflicting results concerning the changes in interaction intensity across gradients may be due to how researchers incorporate effects of plant litter in their studies. Litter is another very important factor in determining recruitment patterns across environments and may thus influence interaction intensity.

Removal studies addressing vegetation effects do not treat litter effects uniformly; in fact, many do not specify whether or not litter was removed along with live vegetation (Goldberg 1987a; Tilman 1989; Wilson \& Tilman 1991; Bertness \& Shumway 1993; Wilson 1994). If litter is removed along with vegetation, comparison of this removal with control conditions quan-

(C) 1999 British Ecological Society, Journal of Ecology, 87, 436-449 tifies the total effects of both vegetation and litter. These total effects are the net balance of the direct effects of each, the indirect effect of one on the other, and any interaction modifications (sensu Wootton 1993; Fig. 2a). Studies that remove only vegetation and leave litter intact assess the net balance of the direct effect of vegetation, its indirect effect on litter and the modification of the litter effect, as well as the indirect effect and interaction modification of litter on vegetation (Fig. 2b). The direct effect of live vegetation in the absence of any influence of litter is seldom addressed. Although these comparisons differ in the interactions with litter that they encompass, they have not been distinguished as measures of interaction intensity. This lack of differentiation may be problematic because the mechanisms through which litter and vegetation affect resources are often very distinct (Facelli \& Pickett 1991). Hence, patterns of interaction intensity across environmental gradients may be very different depending on if, and how, litter effects are incorporated.

It has become clear that litter can strongly influence community structure, although little work has tested empirically how these effects vary across environments. Litter is often thought to interfere with the emergence and growth of seedlings (Knapp \& Seastedt 1986; Bergelson 1990; Carson \& Peterson 1990) because they may face altered germination cues (Grime \& Jarvis 1975), endure phytotoxic effects of the litter leachate (Van der Valk 1986), grow under low light levels, and/or devote energy and time to penetrate the mat (Facelli \& Pickett 1991). Thus, increased competitive intensity in productive areas may not be solely due to the direct result of resource competition, but also the result of litter accumulation due to past productivity (Tilman 1987; Carson \& Peterson 1990; Foster \& Gross 1997). However, in unproductive environments these costs may be outweighed by increased shading, and thus increased water availability (Fowler 1986, 1988; Knapp \& Seastedt 1986). These arguments predict that effects of litter would be facilitative in less productive areas but would become negative as productivity increases (Carson \& Peterson 1990; Barton 1993; Foster \& Gross 1997; Fig. 1b).

Because litter does have strong effects under some conditions, how litter is incorporated into studies of interactions across productivity gradients could strongly influence tests of the predictions described previously. In this paper, we present results of a field experiment designed to examine the direct and indirect effects of vegetation and litter in replicate sites of several community types that differ in a range of environmental characteristics related to productivity. Focusing on the recruitment phase, we asked three questions. (i) Do recruitment levels and the effects of vegetation and litter on recruitment levels vary along this productivity gradient? (ii) If so, how does the incorporation of different types of interactions with litter affect variation in interaction intensity across the gradient? (iii) Is this variation consistent with any of the predictions above? 

gradients

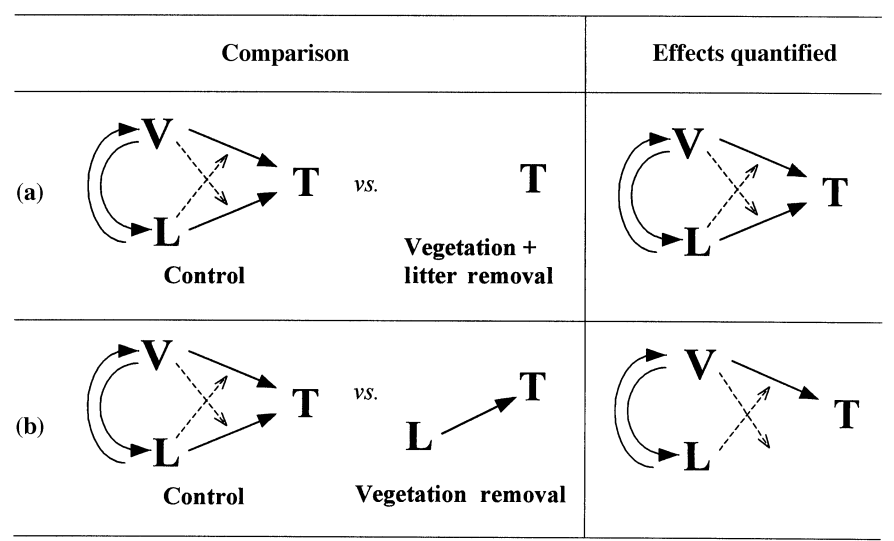

Fig. 2 Common treatment comparisons and quantified effects in removal experiments aimed at measuring competitive intensity: (a) vegetation removal, leaving litter intact, and (b) total removal, clearing both litter and vegetation. $\mathrm{V}$ indicates vegetation, $\mathrm{L}$ indicates litter, and $\mathrm{T}$ indicates the target individual or group of individuals whose response is being measured. Solid arrows signify direct effects, and dashed arrows indicate interaction modifications or higher order effects.

Most studies have used short-term growth of individuals of one or a few long-lived perennial species to test these hypotheses concerning patterns along productivity gradients (Goldberg et al. 1999). In this study, we tested whether any of these hypothesis are consistent with patterns of early emergence and survival of the entire seedling community. It is important to test these predictions in a range of life-history stages to be able to interpret the population consequences of local processes (Peckarsky et al. 1997; Goldberg et al. 1999). For instance, Goldberg et al. (1999) found that plant survival may show different patterns of competitive intensity along productivity gradients from those exhibited by plant growth. Moreover, examining community-wide patterns, although it misses species-specific information, is more representative of the response of the whole community than a study of one or two species from that community.

\section{Materials and methods}

\section{SITE DESCRIPTION}

We studied three herbaceous community types that spanned a range of productivity conditions characteristic of herbaceous communities in the upper midwest of the USA: fens, prairies and sand barrens. Fens are wetland communities characterized by upwelling and calcareous surface water flow and dominated by sedges. Prairies are terrestrial grassland communities dominated by tall warm-season grasses. Sand barren communities, the most xeric of the three community types, have a well-drained, sandy till substrate and are dominated by small graminoids and forbs. For each community type, we chose two representative sites, for a total of six sites, in south-eastern Michigan and northern Ohio (Table 1).

\section{EXPERIMENTAL DESIGN}

At each site, we selected at random three $1-\mathrm{m}^{2}$ experimental blocks from a grid of 20 blocks with vegetation and environmental conditions characteristic of the site. No block was closer than $2 \mathrm{~m}$ or further than $15 \mathrm{~m}$ from any other block. We then subdivided the blocks into four $0.16-\mathrm{m}^{2}$ plots, with $0.2-\mathrm{m}$ buffer zones between plots within a block. Thus, we had two levels of spatial replication: sites within community types and blocks within sites. Before conducting any manipulations, in June 1995, we assessed the vegetative (by species) and litter cover of each block with a point quadrat frame (100 points $\left.\mathrm{m}^{-2}\right)$.

Treatments consisted of all possible combinations of two levels of adult vegetation (natural and removed) and two levels of litter (natural and removed), with the four treatment combinations randomly assigned to plots within each block. We removed vegetation by applying a systemic herbicide (Roundup, Monsanto Corp., St. Louis, MO) and then collecting the killed vegetation, except in the fen sites where we clipped the vegetation weekly, or as needed throughout the season, to avoid the possible detrimental effects of Roundup in the wetland system. We removed litter by clipping around the plots and removing the dead growth from previous years. Treatments were completed by 2 July 1995 . After the vegetation and litter had been removed, they were dried for $48 \mathrm{~h}$ at $60{ }^{\circ} \mathrm{C}$ and weighed to estimate plot productivity (see the analysis section). Because the vegetation and litter were collected during the middle of the growing season, absolute levels were relatively low compared to other studies that harvested standing
Journal of Ecology, 87, 436-449 
K. Nash Suding \& D.E. Goldberg
Table 1 Vegetation and litter characteristics of the six study sites. Sites that have a letter in common do not differ significantly in the specified characteristic $(P>0.05$, Tukey's HSD). Values are presented as means \pm 1 standard error. Vegetation and litter were harvested in late June $(n=3$ for each site)

\begin{tabular}{|c|c|c|c|c|c|}
\hline $\begin{array}{l}\text { Community } \\
\text { type/site }\end{array}$ & Location & $\begin{array}{l}\text { Vegetation } \\
\text { mass }\left(\mathrm{g} \mathrm{m}^{-2}\right)\end{array}$ & $\begin{array}{l}\text { Litter mass } \\
\left(\mathrm{g} \mathrm{m}^{-2}\right)\end{array}$ & $\begin{array}{l}\text { Litter } \\
\text { cover }(\%)\end{array}$ & $\begin{array}{l}\text { Dominant species } \\
(>10 \% \text { cover })\end{array}$ \\
\hline Fen 1 & $\begin{array}{l}42^{\circ} 23^{\prime} 30^{\prime \prime} \mathrm{N} \\
84^{\circ} 03^{\prime} 30^{\prime \prime} \mathrm{E}\end{array}$ & $180.3 \pm 56.1 \mathrm{a}$ & $145.2 \pm 38.4 \mathrm{ab}$ & $68 \pm 1.5 \mathrm{a}$ & $\begin{array}{l}\text { Eleocharis rostellata } \\
\text { Scirpus acutus }\end{array}$ \\
\hline Fen 2 & $\begin{array}{l}42^{\circ} 23^{\prime} \mathrm{N} \\
84^{\circ} 03^{\prime} 45^{\prime \prime} \mathrm{E}\end{array}$ & $159.2 \pm 16.6 \mathrm{a}$ & $190.7 \pm 60.8 \mathrm{a}$ & $74.3 \pm 8.3 \mathrm{a}$ & $\begin{array}{l}\text { Eleocharis rostellata } \\
\text { Potentilla fruticosa }\end{array}$ \\
\hline Prairie 1 & $\begin{array}{l}42^{\circ} 20^{\prime} \mathrm{N} \\
83^{\circ} 55^{\prime} \mathrm{E}\end{array}$ & $58.7 \pm 13.7 b$ & $212.0 \pm 26.9 \mathrm{a}$ & $89.7 \pm 4.8 b$ & $\begin{array}{l}\text { Andropogon gerardii } \\
\text { Sysrinchium albidumi }\end{array}$ \\
\hline Prairie 2 & $\begin{array}{l}42^{\circ} 15^{\prime} \mathrm{N} \\
83^{\circ} 40^{\prime} 30^{\prime \prime} \mathrm{E}\end{array}$ & $68.8 \pm 21.8 b$ & $127.5 \pm 16.5 b$ & $49.3 \pm 1.5 \mathrm{c}$ & $\begin{array}{l}\text { Andropogon gerardii } \\
\text { Poa compressa }\end{array}$ \\
\hline Sand Barren 1 & $\begin{array}{l}41^{\circ} 30^{\prime} 30^{\prime \prime} \mathrm{N} \\
83^{\circ} 33^{\prime} 30^{\prime \prime} \mathrm{E}\end{array}$ & $77.3 \pm 13.8 b$ & $55.6 \pm 12.6 \mathrm{c}$ & $73.7 \pm 8.6 \mathrm{a}$ & $\begin{array}{l}\text { Liatris spicata } \\
\text { Fragaria virginiana }\end{array}$ \\
\hline Sand Barren 2 & $\begin{array}{l}42^{\circ} 24^{\prime} 30^{\prime \prime} \mathrm{N} \\
83^{\circ} 59^{\prime} 30^{\prime \prime} \mathrm{E}\end{array}$ & $45.1 \pm 2.8 b$ & $13.2 \pm 2.3 \mathrm{c}$ & $85.3 \pm 2.9 b$ & $\begin{array}{l}\text { Centaurea maculata } \\
\text { Liatris spicata } \\
\text { Hypericum perforatum }\end{array}$ \\
\hline
\end{tabular}

crop estimates at the end of the growing season (Wilson \& Keddy 1986; Foster 1999). However, these measures should be an accurate estimate of relative plot productivity because the temporal patterns of vegetation and litter accumulation appeared to be similar at each site (K. Suding, personal observation).

\section{DATA COLLECTION}

Seedlings originally present in each plot were killed in the treatments where Roundup was applied but not in the other treatments. To account for this difference in initial seedling density, we marked the original seedlings on 5-8 July 1995. We then censused newly emerging seedlings on 10-15 August 1995 (census 1) and on 9-17 September 1995 (census 2). At each census, we counted and marked all newly emerged seedlings with toothpicks coded for the census date, and recorded the number of surviving seedlings from the previous cohorts. Light levels at the soil surface in each of the plots were measured with a Sunfleck Ceptometer (Decagon, Pullman, WA) at census 2.

\section{ANALYSIS}

Because this study compares community types that may differ in the degree of above-ground biomass accumulation between years, standing crop alone is not necessarily a good surrogate of productivity. Instead, we used an aggregate of three variables that are potentially related to productivity: relative light availability (percentage photosynthetically active radiation; \%PAR), dead above-ground (litter) mass, and living above-ground (vegetation) mass. We carried out a principal components analysis (PCA) to reduce these three highly correlated variables into a composite measure of productivity.
Seedling emergence and survivorship were compared among treatments and community types (fixed effects) and sites (nested within community type) with nested ANOVA models (Sokal \& Rohlf 1995). We analysed four dependent variables: the number of seedlings per plot emerging in each cohort (1 and 2); the percentage survival of cohort 1 to census 2 ; and the total number of seedlings present at census 2 (net recruitment). Because censuses were taken 1 month apart, emergence variables incorporated short-term seedling survival. Arcsine square-root transformation of the survivorship values satisfied assumptions of normality. No other serious departures from the assumptions of normality and homogeneity were evident, although the emergence data were moderately skewed to the right due to zero counts. To assess variability in recruitment levels among sites, we also constructed random effect ANOVA models in which recruitment levels for each treatment combination (control, completely cleared, vegetation only removed, litter only removed) were compared separately among community types (fixed) and sites (nested within community types).

We used a number of indices of the magnitude of competitive or facilitative effects on emergence and survival in order to compare these effects across sites and community types. The first set of indices of interaction intensity measures the direct effect of either vegetation or litter, by comparing performance in the presence of only vegetation or only litter relative to the completely cleared treatment (no interactions) (Fig. 3, numbers 1 and 2). The second set of indices incorporates indirect interactions and interaction modifications, as well as direct effects, by comparing performance in the presence of only vegetation or only litter relative to the control (all interactions present) (Fig. 3, numbers 3 and 4). We included both analyses
Ecological Society, Journal of Ecology, 87, 436-449 


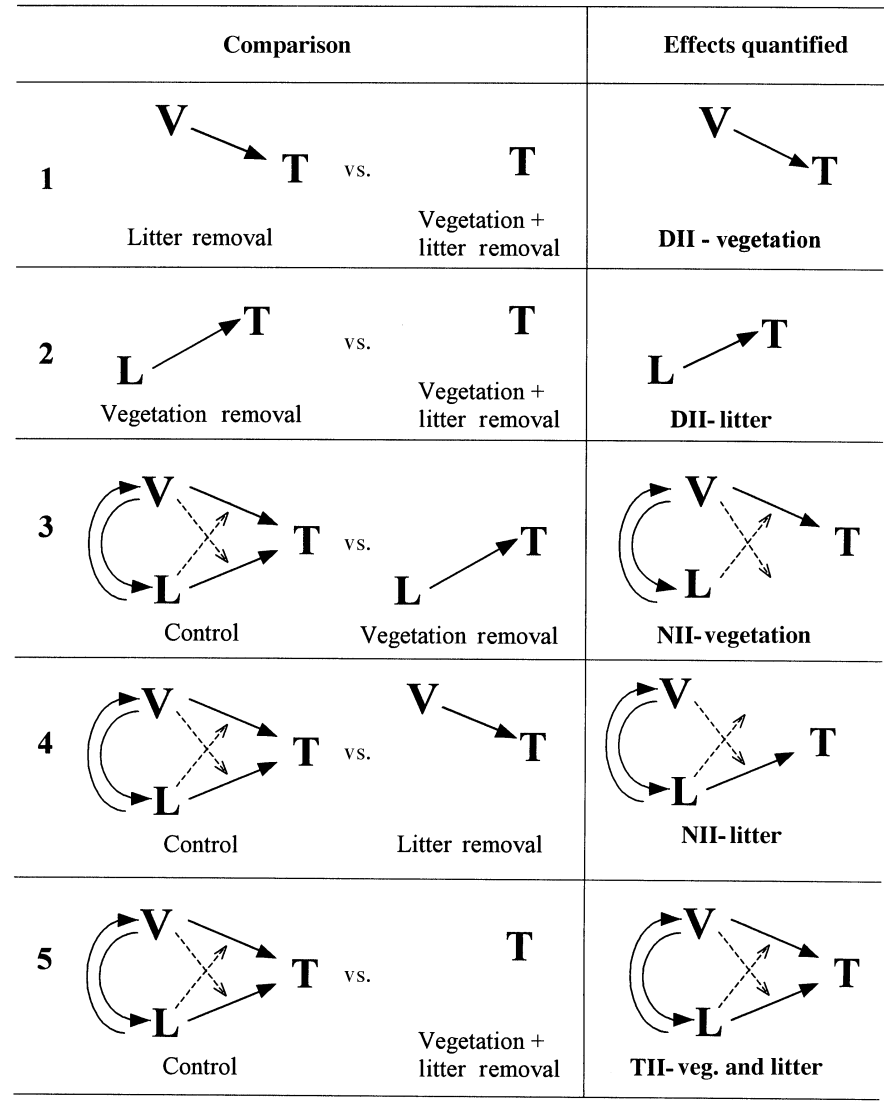

Fig. 3 The interactions in the treatments compared, and the effects quantified by the comparisons, for each of the indices used in this study: (1) DII-vegetation; (2) DII-litter; (3) NII-vegetation; (4) NII-litter; (5) TII-vegetation and litter. Abbreviations and symbols are the same as in Fig. 2.

because there is no reason to assume that they should show identical patterns. In addition to calculating the effects of vegetation and litter separately for each of these indices, we also calculated a measure of the total interaction (vegetation and litter) intensity relative to the cleared treatment (Fig. 3, number 5). This is the index reported in studies where both vegetation and litter are removed and is one of the most common measures of competitive intensity in removal experiments (Wilson \& Keddy 1986; Turkington et al. 1993; Belcher et al. 1995).

The direct interaction indices (DII) were calculated as:

DII vegetation $=\left(\mathrm{V}^{+} \mathrm{L}^{-}-\mathrm{V}^{-} \mathrm{L}^{-}\right) /$

$$
\left(\max \mathrm{V}^{+} \mathrm{L}^{-} \text {or } \mathrm{V}^{-} \mathrm{L}^{-}\right)
$$

DII litter $=\left({ }^{-} \mathrm{L}^{+}-\mathrm{V}^{-} \mathrm{L}^{-}\right) /\left(\max \mathrm{V}^{-} \mathrm{L}^{+}\right.$or $\left.\mathrm{V}^{-} \mathrm{L}^{-}\right)$

The net interaction indices (NII) were calculated as:

NII vegetation $=\left(\mathrm{V}^{+} \mathrm{L}^{+}-\mathrm{V}^{-} \mathrm{L}^{+}\right) /$

$$
\left(\max \mathrm{V}^{+} \mathrm{L}^{+} \text {or } \mathrm{V}^{-} \mathrm{L}^{+}\right)
$$

NII litter $=\left(\mathrm{V}^{+} \mathrm{L}^{+}-\mathrm{V}^{+} \mathrm{L}^{-}\right) /\left(\max \mathrm{V}^{+} \mathrm{L}^{+}\right.$or $\left.\mathrm{V}^{+} \mathrm{L}^{-}\right)$
And the total interaction index (TII) was calculated as:

TII vegetation and litter $=\left(\mathrm{V}^{+} \mathrm{L}^{+}-\mathrm{V}^{-} \mathrm{L}^{-}\right) /$

$$
\left(\max \mathrm{V}^{+} \mathrm{L}^{+} \text {or } \mathrm{V}^{-} \mathrm{L}^{-}\right)
$$

where $\mathrm{V}^{+}$or $\mathrm{V}^{-}$represents adult vegetation present or removed, and $\mathrm{L}^{+}$or $\mathrm{L}^{-}$represents litter present or removed, respectively. Because the denominator is the maximum of the two values being compared in the numerator, all three types of indices are symmetrical around 0 , ranging from +1 (maximum facilitation, performance minimal in removals) to -1 (maximum competition, performance minimal in controls). These indices thus weight positive and negative effects of neighbour removal in the same way (Markham \& Chanway 1996). For example, a RII of 0.5 would indicate that performance was twice as high in control compared with removal treatments (i.e. facilitation) and a RII of -0.5 would indicate that performance was twice as high in removal compared to control treatments (i.e. competition).

Figure 3 shows the interactions present in the treatments compared, and the effects quantified by the comparisons, for each of the indices. Although we refer to higher order interactions as interaction modi- 
fications (sensu Wootton 1993) throughout this paper, we are unable to distinguish between a quantitative change in a direct interaction or a non-linear direct interaction. Neither can we distinguish between these modifications and indirect effects.

We evaluated whether productivity, as quantified by the composite PCA index, was related to recruitment within each treatment and to the intensity of treatment effects as measured by the interaction indices (direct, net and total). We constructed first-order regression models between either the indices or recruitment levels and the first principle component (axis 1) at each of three spatial scales: within each community type ( $n=6$ for each community type); among site means for all three community types ( $n=6$ overall); and among and within the sites (i.e. among plots, $n=18$ ). Although the last level of comparison, among and within sites, has several levels of non-independence among the data points, it is still of interest to see if a single factor can account for variation both within and among sites. Significance levels were adjusted by the Bonferroni procedure.

\section{Results}

\section{RELATIONSHIPS AMONG PRODUCTIVITY VARIABLES}

PCA reflected the strong correlations among the three variables related to productivity (Fig. 4). The first axis accounted for $54 \%$ of all variation; high scores reflected plots with high biomass accumulation both during the current year (vegetation mass) and the previous years (litter mass) and low light levels. These variables were all significantly correlated with each other (Spearman's rank correlation, $P<0.05$; unpublished data). On the first PCA axis, plots at the two sand barrens sites had low scores (low productivity) and those at the two fen sites had high scores (high productivity), with the plots at the prairie sites intermediate (Fig. 4). Relationships with just the standing crop of the current year (vegetation mass) did not explain patterns in interaction intensity (see below) as well as this composite index did (K. Suding, unpublished data).

The second axis accounted for an additional 27\% of the variance and explained additional variation primarily among the sites with higher productivity (i.e. prairie and fen), possibly encompassing smallerscale variation in the rates of litter and vegetation accumulation within these sites. Because the first PCA axis encompassed most of the variation in the data set and clearly reflected a productivity gradient, we related patterns in recruitment and interaction intensity only to the first axis.

\section{SPATIAL VARIATION IN RECRUITMENT PATTERNS}

Emergence, but not survival, varied spatially and among treatments in this study (Table 2). The dynamics of the emergence of cohort 1 and net recruitment were similar (Table 2), largely because cohort 1 was $35-62 \%$ bigger than cohort 2 and responded more strongly, although in a fashion similar to cohort 2 , to the treatments. Thus, we focused on the relationships between emergence of cohort 1 and productivity.

Within each of the four treatments, the emergence

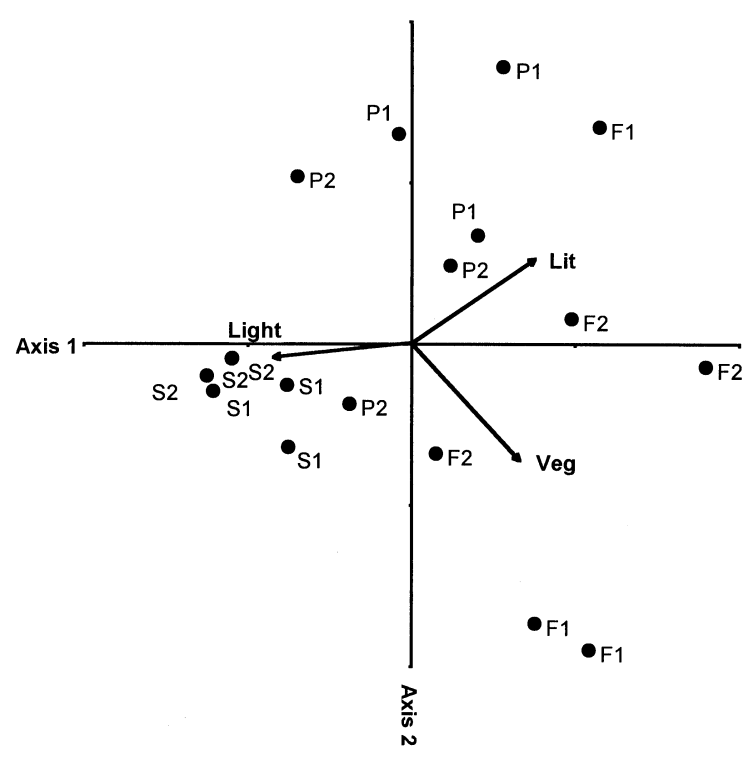

Fig. 4 Principal components for environmental variables among and within sites. Each point represents a plot at one site: S1 and $\mathrm{S} 2$ represent sand barren sites; P1 and P2 prairie sites; F1 and F2 fen sites (see Table 1). The first unrotated axis explains $54 \%$ of all variation in environmental variables; the second axis explains an additional $24 \%$ of all variation. The endpoint of the arrows indicates component loadings for each of the environmental variables on the two axes. Abbreviations: Light, light availability; Lit, litter mass; Veg, vegetation mass. 
Vegetation and litter effects across gradients
Table 2 ANOva testing the influence of community, site and removal treatments on emergence of cohorts 1 and 2, the survival of cohort 1 to census 2 , and net recruitment (the final number of seedlings alive at census 2). The dependent variable columns show $F$-values and significance $\left({ }^{+} P<0.1 ; * P<0.05\right.$; ** $P<0.01$; *** $\left.P<0.001\right)$

\begin{tabular}{lccccc}
\hline Source & d.f. & $\begin{array}{l}\text { Emergence of } \\
\text { cohort } 1\end{array}$ & $\begin{array}{l}\text { Emergence } \\
\text { of cohort 2 }\end{array}$ & $\begin{array}{l}\text { Survival of } \\
\text { cohort 1 to census 2 }\end{array}$ & $\begin{array}{l}\text { Net } \\
\text { recruitment }\end{array}$ \\
\hline Spatial effects & & & & & $11.56^{* *}$ \\
Community & 2 & $12.21^{* * *}$ & $11.76^{* * *}$ & 0.46 & $6.10^{* *}$ \\
Site (community) & 3 & $23.97^{* * *}$ & $2.92^{*}$ & 1.01 & 1.55 \\
Block (site) & 12 & $3.56^{* *}$ & 0.60 & 1.30 & $1.21^{* *}$ \\
Treatment effects & & & & & 12.22 \\
Litter & 1 & 0.41 & 0.10 & 0.70 & $3.61+$ \\
Vegetation & 1 & $34.13^{* * *}$ & 1.19 & 0.02 & 1.26 \\
$\mathrm{~L} \times \mathrm{V}$ & 1 & $3.54+$ & 1.52 & 0.03 & $5.24^{*}$ \\
$\mathrm{~L} \times \mathrm{C}$ & 2 & 1.43 & 0.16 & 0.16 & 0.21 \\
$\mathrm{~V} \times \mathrm{C}$ & 3 & $7.17^{* *}$ & $3.19+$ & 0.97 & 1.69 \\
$\mathrm{~L} \times \mathrm{S}(\mathrm{C})$ & 2 & 0.40 & 0.07 & 0.62 & 0.01 \\
$\mathrm{~V} \times \mathrm{S}(\mathrm{C})$ & 3 & $5.57^{* *}$ & 1.58 & 1.82 & 0.35 \\
$\mathrm{~L} \times \mathrm{V} \times \mathrm{C}$ & 2 & 1.06 & 0.05 & 0.42 & \\
$\mathrm{~L} \times \mathrm{V} \times \mathrm{S}(\mathrm{C})$ & 3 & 0.19 & 0.49 & 0.23 & \\
Error & 39 & & & & \\
\hline
\end{tabular}

of cohort 1 (Fig. 5) and net recruitment (K. Suding, unpublished data) differed significantly among sites within community types, but only the control (and marginally for litter removal) differed significantly among community types. The large standard errors for mean emergence at many of the sites reflected further variation among blocks within sites (Fig. 5). This spatial variation in emergence was not sig- nificantly related ( $P>0.15$ for all comparisons) to productivity, as represented by PCA axis 1 , on any spatial scale (among and within sites, among site means, or within community types) (Fig. 6). However, the maximum rate of emergence (regardless of community type or site) within the control and litter removed treatment tended to increase with productivity, as indexed by PCA axis 1 (Fig. 6).

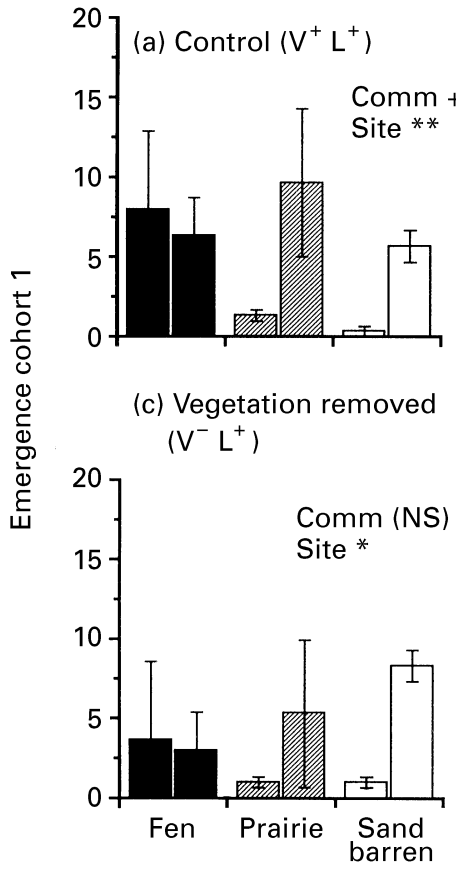

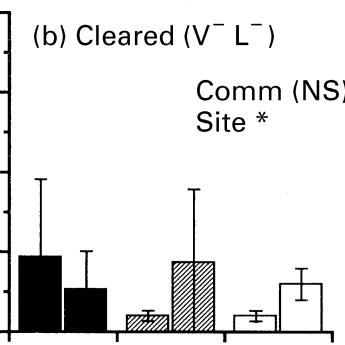

(d) Litter removed $\left(\mathrm{V}^{+} \mathrm{L}^{-}\right)$

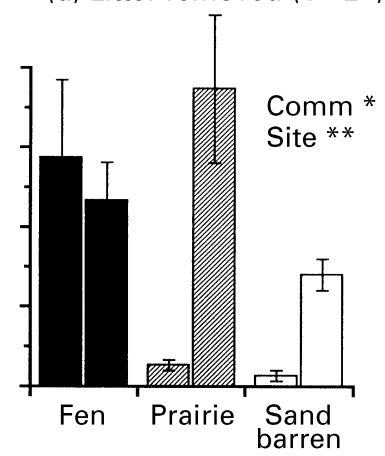

(C) 1999 British Ecological Society, Journal of Ecology, 87, 436-449
Fig. 5 Emergence of cohort 1 (i.e. the number of seedlings at census 1) in the four treatments: (a) control plots, (b) litter removed, (c) vegetation removed, (d) cleared (both litter and vegetation removed) plots. Solid bars, fen; striped bars, prairie; white bars, sand barren. Site 1 is the left bar for each community type (comm). Error bars represent one standard error. Results of ANOVA models within each treatment are shown: NS (non-significant); ${ }^{+} P<0.10,{ }^{*} P<0.05,{ }^{* *} P<0.01 . \mathrm{V}^{-}$, vegetation removed; $\mathrm{V}^{+}$, vegetation present; $\mathrm{L}^{-}$, litter removed; $\mathrm{L}^{+}$, litter present. 
443

K. Nash Suding \& D.E. Goldberg
C) 1999 British Ecological Society, Journal of Ecology, 87, 436-449
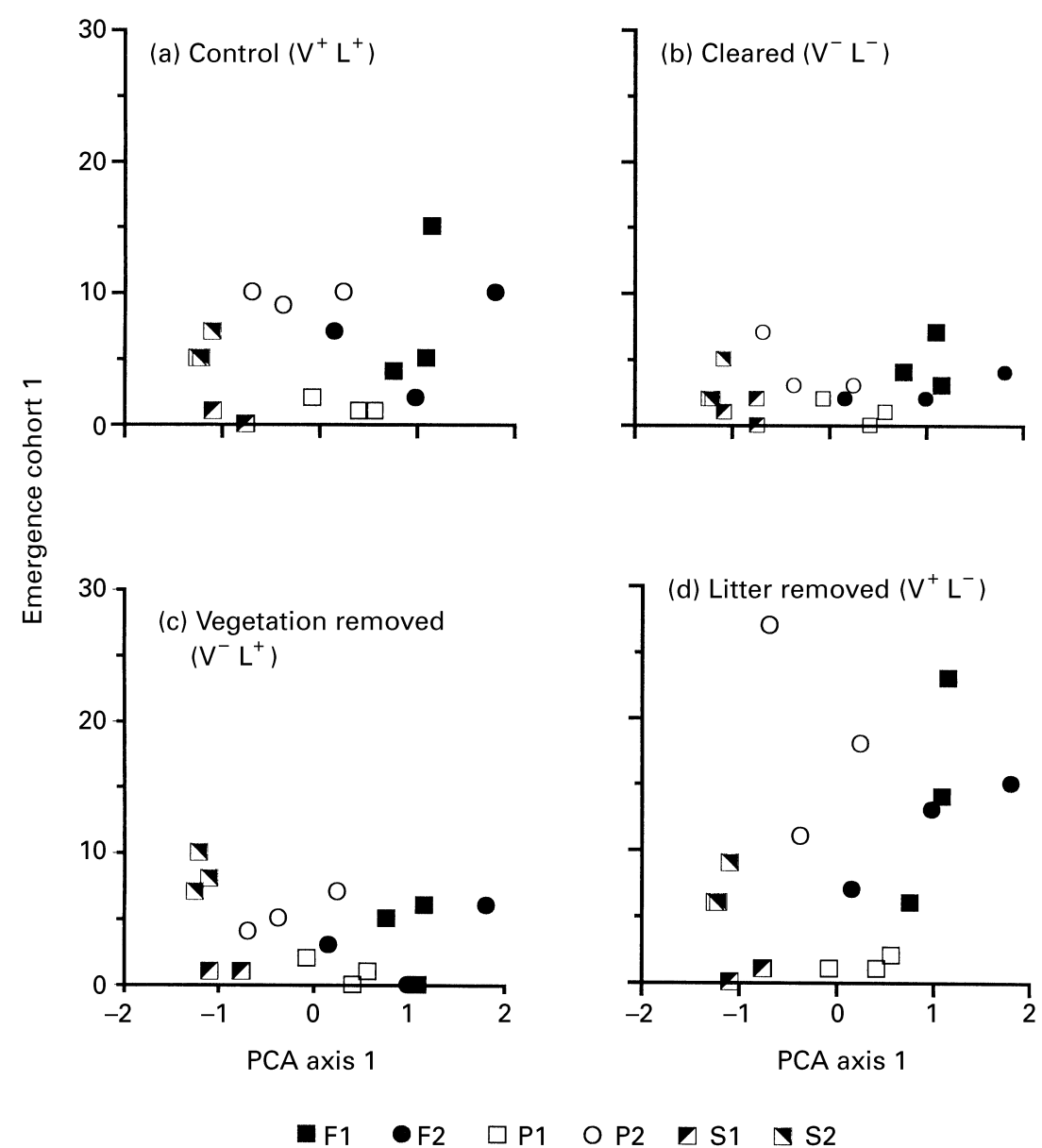

Fig. 6 Relationships of emergence of cohort 1 with PCA axis 1 (productivity axis) for each of the four treatments. No significant relationships existed among all plots, among site means, or within a community type.

Emergence varied the most, and reached the highest levels in litter removal $\left(\mathrm{V}^{+} \mathrm{L}^{-}\right)$plots (Fig. 6d).

\section{EFFECTS OF THE EXPERIMENTAL REMOVAL} OF VEGETATION AND LITTER

The presence of vegetation significantly facilitated emergence of cohort 1 and net recruitment overall, although emergence was only significantly increased at half of the sites (significant vegetation-site interaction; Table 2) and in one of the community types (significant vegetation $\times$ community type interaction; Table 2). Vegetation in both fen sites facilitated the emergence of seedlings in cohort 1 , while vegetation had minimal effects in either direction at sand barren sites (Fig. 7a). The significant vegetation by site interaction was probably due to the large difference between the two prairie sites, one of which showed facilitative effects of vegetation and one of which was unaffected by the presence or absence of vegetation.

In contrast, litter did not appear to affect any of the dependent variables, nor did its effect differ among sites or community types (Table 2). However, there was some evidence of an interaction between litter and vegetation $(P<0.10)$ for emergence of cohort 1 and net recruitment (Table 2); the facilitative effect of vegetation on emergence may be reduced in the presence of litter (Fig. 7b).

\section{VARIATION OF TREATMENT EFFECTS ACROSS} THE PRODUCTIVITY GRADIENT

Litter and vegetation, alone (DII) or in combination (TII), generally facilitated recruitment (Fig. 8). However, inclusion of indirect interactions and interaction modifications frequently caused the net effect of both vegetation and litter (NII-vegetation and NII-litter, respectively) to become negative, with the exception of the NII-vegetation at high productivity, which remained positive (Fig. 8).

Neither the direct nor the net effects of litter were significantly correlated with productivity on any spatial scale, although there were some trends $(P<0.05$, adjusted alpha $=0.01)$ towards decreasing direct or net effect of litter with increasing productivity (Table 3). The overall lack of relationships was consistent with the lack of significant interactions of litter treatment with site or community type (Table 2).

In contrast, the net effect of vegetation (NII-vegetation) significantly increased with productivity 
Vegetation and litter effects across gradients

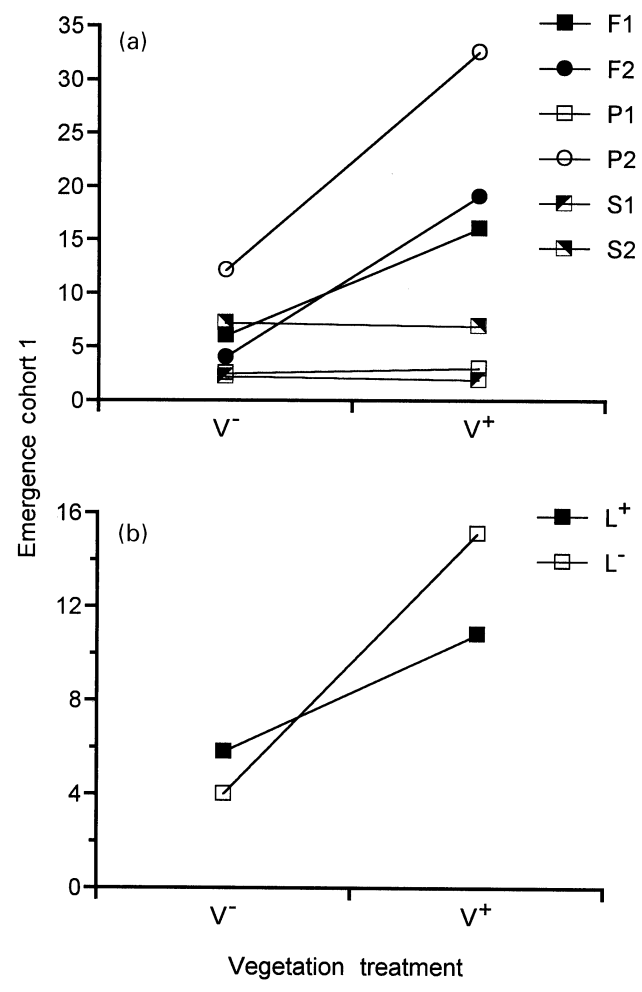

Fig. 7 Interaction plots for emergence of cohort 1: (a) vegetation removal affected the emergence of cohort 1 differently depending on the sites $(P<0.05)$ and community type $(P<0.05)$, although it was generally facilitative; and (b) litter removal marginally influenced the effect of vegetation removal on the emergence of cohort $1(P<0.10)$.

when all community types were included in a single analysis (among site means or among all plots; Table 3 and Fig. 8). Vegetation inhibited recruitment at low productivity but became increasingly facilitative as productivity increased. However, this relationship was only found in the presence of litter. In the absence of litter, the direct effect of vegetation was not related to productivity on any spatial scale (Table 3 and Fig. 8).

The total effects of vegetation and litter were (TII) also not related to the productivity axis at any scale (Table 3 and Fig. 8).

\section{Discussion}

\section{PATTERNS ALONG PRODUCTIVITY GRADIENTS}

Results from this experiment do not fully support any of the predictions in Figure 1, indicating that there may be many alternatives for explaining community response along productivity gradients other than the ones usually hypothesized. However, our results do partially support two of the predictions. First, direct effects of vegetation did not vary consistently with productivity, which agrees with the prediction by Tilman (1988), although in our case the interactions were generally facilitative rather than competitive (DII- vegetation; Fig. 8). Secondly, the direct effect of litter was weakly correlated with productivity, as Carson \& Peterson (1990) would predict (DII-litter; Table 3), although the effect only became negative in very productive environments, generally being less facilitative as productivity increased.

Our results may only partially support these predictions because facilitative effects are common across the entire productivity gradient, in contrast to other studies of interaction strength along productivity gradients. These strong facilitative effects may be due to our focus on a very early life stage. Facilitation of seedling emergence and survival by adult neighbours has been found in a number of environments, including deserts (Franco \& Noble 1989; Valiente-Banuet et al. 1991), woodlands (DeSteven 1991a; Callaway 1992; Kellman \& Kading 1992), salt marshes (Bertness \& Hacker 1994) and grasslands (Fowler 1988; Greenlee \& Callaway 1996) (for an exception see Foster 1999 in old-fields). However, most studies of interactions along productivity gradients have been conducted with plants past the initial establishment stage and have quantified effects on growth rather than on establishment or survival (Goldberg et al. 1999). Growth of juveniles or adults may not always be the critical parameter for determining patterns of distribution and abundance (Grubb et al. 1982), and effects of plant-plant interactions may differ consistently between life history stages and demographic parameters (Gurevitch 1986; DeSteven 1991a,b; T. Howard, unpublished data). Therefore, it is important that a range of life-history stages be studied.

Seedling establishment may be more sensitive to abiotic stresses than other life-history stages (Callaway \& Walker 1997), causing interactions that were originally facilitative to switch to being predominantly competitive as seedlings age (McAuliffe 1984; Valiente-Banuet et al. 1991; Bertness \& Yeh 1994; Berkowitz et al. 1995). As this switch occurs, the relationships between interaction intensity and productivity found here could either follow the original trajectory (i.e. the same linear relationship as magnitude changes) or change altogether (i.e. a qualitatively different relationship). If the direction of relationships remains similar as the magnitude of the effects grows more competitive, then our results would be consistent with the predictions by Tilman (1988) for vegetation effects and Carson \& Peterson (1990) for litter effects.

Most other work testing the relationship between interaction intensity and productivity involves artificially created nutrient gradients at one site (Wilson \& Shay 1990; Wilson \& Tilman 1991, 1995) or natural gradients within a single community type (Gurevitch 1986; Twolan-Strutt \& Keddy 1996; Foster \& Gross 1997). This study is one of the few designed to test specifically patterns both within and among community types. Patterns between interaction intensity and productivity within site or community type may 
K. Nash Suding \& D.E. Goldberg
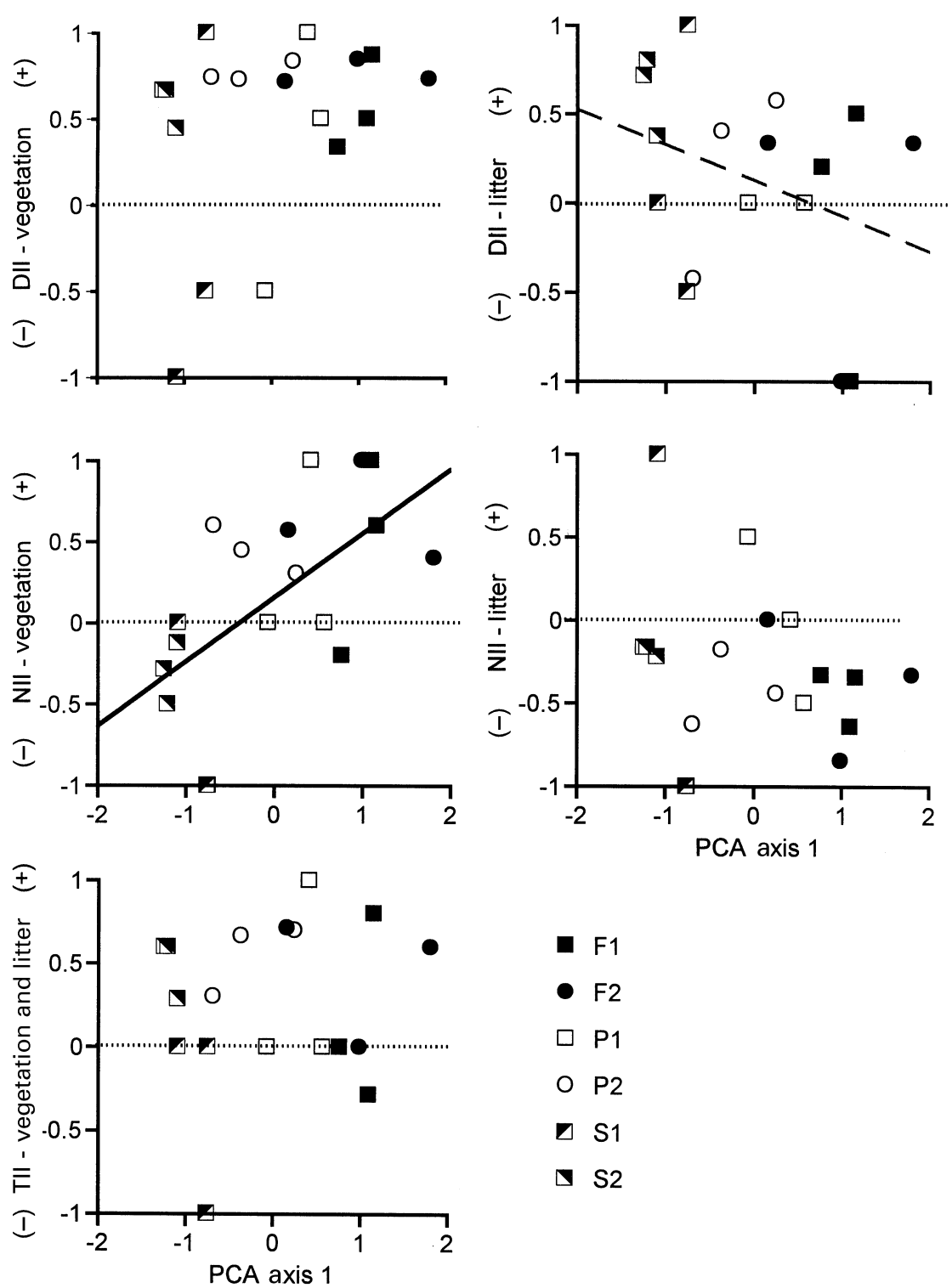

- F1

- F2

$\square \mathrm{P} 1$

O P2

\ $\mathrm{S1}$

$\nabla \mathrm{S} 2$

Fig. 8 Relationships between PCA axis 1 (productivity axis) and indices of interaction intensity for the emergence of cohort 1 : the direct interaction index (DII) for vegetation and for litter; the net interaction index (NII) for vegetation and for litter, and the total interaction index (TII) for both vegetation and litter. The solid line indicates a significant relationship using all 18 plots in a single regression (Bonferroni-adjusted alpha, $P<0.01$ ), the dashed line indicates a marginally significant relationship (Bonferroni-adjusted alpha, $P<0.05$ ). Table 3 describes relationships at all spatial scales. The dotted line, zero interaction intensity, indicates no effect of interactions; values greater than zero are facilitative and values less than zero are competitive.

Table 3 Relationships between the direct, net and total interaction indices and the first PCA axis at three spatial scales: within each community type, among the sites, and among all plots. $R$-values from linear regressions of interaction indices with the axis scores are given for each comparison $\left({ }^{+} P<0.05,{ }^{*} P<0.01,{ }^{*} P<0.005\right)$. $P$-values are based on Bonferroni-adjusted alphas for each series of comparisons; significant relationships have an adjusted $P$-value $<0.01$ (alpha $=0.05 / \mathrm{k}=5)$. Bold type shows significant (or marginally so) relationships, of which the among and within site relationships are illustrated further in Fig. 8

\begin{tabular}{lllllll}
\hline $\begin{array}{l}\text { Spatial } \\
\text { comparison }\end{array}$ & $n$ & $\begin{array}{l}\text { DII- } \\
\text { vegetation }\end{array}$ & $\begin{array}{l}\text { NII- } \\
\text { vegetation }\end{array}$ & $\begin{array}{l}\text { DII- } \\
\text { litter }\end{array}$ & $\begin{array}{l}\text { NII- } \\
\text { litter }\end{array}$ & $\begin{array}{l}\text { TII-veg } \\
\text { and litter }\end{array}$ \\
\hline Within community & & & & & & \\
$\quad$ Fen & 6 & +0.026 & -0.032 & -0.045 & $-\mathbf{0 . 8 3 3}^{+}$ & -0.465 \\
$\quad$ Prairie & 6 & +0.060 & -0.042 & +0.361 & +0.095 & +0.033 \\
$\quad$ Sand barren & 6 & +0.779 & -0.632 & +0.473 & $-\mathbf{0 . 8 8 4}^{+}$ & -0.045 \\
Among sites & 6 & +0.550 & $+\mathbf{0 . 9 3 6}^{*}$ & $-\mathbf{0 . 8 2 3}^{+}$ & -0.179 & +0.366 \\
Among and within sites & 18 & +0.414 & $\mathbf{+ 0 . 5 9 7}^{*}$ & $-0.489^{+}$ & -0.241 & +0.185 \\
\hline
\end{tabular}

(C) 1999 British Ecological Society, Journal of Ecology, 87, 436-449 
Vegetation and litter effects across gradients

(C) 1999 British Ecological Society, Journal of Ecology, 87, 436-449 differ from those across community types, similar to how the relationship between diversity and productivity changes across spatial scales (G. Mittlebach, personal communication; Moore \& Keddy 1989). Because we used two replicate sites within each community type and three blocks within each site, this study is a relatively weak test of the relationship between interaction intensity and productivity at these spatial scales. An experiment that included more replicate sites within each community type and more replicate blocks within each site would be necessary to test this pattern further. However, even with this level of replication we did find significant differences in seedling emergence between community types and sites. Moreover, greater replication within each community type would probably not change the result that interaction intensity was rarely related to variation in productivity within a community type (least significant number greater than 100 for over $50 \%$ of all correlations).

It is also important to note that measures of interaction intensity in this study refer to response of all the species in the community, an aggregated population response, regardless of species identity. The majority of studies done previously have examined individuallevel (Wilson \& Keddy 1986; Twolan-Strutt \& Keddy 1996) or population-level responses (Campbell \& Grime 1992; Foster 1999) of particular species. Both these may differ among species (Wilson \& Keddy 1986; DiTommaso \& Aarssen 1991; Wilson 1993). Aggregated population responses, although missing the dynamics of single species and confounding simultaneous interference and facilitation among populations, may yield more generalizable results for community-level patterns of interaction intensity across gradients. For example, Foster (1999) found mostly competitive effects of seedling establishment due to both vegetation and litter, while we found largely facilitative effects due mostly to vegetation. One main difference in our studies is that we measured the aggregated population response of the natural community while Foster added seeds of displaced species and measured species-specific responses. Because the species that Foster added were not abundant at any of the sites, this strong competitive effect could explain why these native prairie species have trouble colonizing old-fields. However, the old-field species present in the seed bank and seed rain at these sites may not experience such strong inhibition, and natural seedling establishment could possibly show the same community-level patterns that we found in our study.

\section{SEPARATING VEGETATION AND LITTER} EFFECTS

We know of two other studies (Foster \& Gross 1997; Foster 1999) that have distinguished between the effects of vegetation and litter when examining interaction intensity across a productivity gradient. Foster
\& Gross (1997) found the effect of vegetation to be competitive but generally not related to productivity, supporting the predictions of Tilman (1988). However, when Foster (1999) included very unproductive sites (probably comparable to our sand barren sites), he found a strong decrease in competitive intensity for both seedling establishment and juvenile growth, supporting the predictions of Grime (1979). Both studies (Foster \& Gross 1997; Foster 1999) found litter to be facilitative at low productivity and grow increasingly competitive as productivity increased, even for seedling establishment, supporting the predictions of Carson \& Peterson (1990). The interaction intensity measures they used are similar to our net interaction indices; they did not examine the direct effects of vegetation and litter separately.

Many studies that solely address vegetation effects do not specify whether or not litter was removed along with vegetation (Goldberg 1987a; Tilman 1989; Wilson \& Tilman 1991; Bertness \& Shumway 1993; Wilson 1994). Thus, their estimates of interaction intensity could be either similar to our TII (comparison between controls and complete removal plots) or to our NII-vegetation (comparison between control and plots with only vegetation removed). Because TII includes the direct and indirect effects and interaction modifications of both vegetation and litter, but NII-vegetation excludes the direct effects of litter (Fig. 3), these comparisons clearly have very different interpretations and, as our results show, potentially different patterns. For instance, if this study had looked only at TII, we would conclude that effects are constant across this productivity gradient. We would draw similar conclusions if we looked at vegetation effects in the absence of litter (DII-vegetation). However, when we incorporate the indirect effects of litter into the analysis (NII-vegetation), competition appears to decrease and facilitation to increase with productivity, a relationship not consistent with any of the existing hypotheses in the literature. Although the mechanism is not clear (see below), the pattern may not be unusual. In a meta-analysis incorporating data from 14 studies of competition/facilitation along productivity gradients, Goldberg et al. (1999) found a similar pattern of decreasing competition intensity with productivity and that this pattern was clearest for survival.

\section{SEPARATING DIRECT EFFECTS FROM INDIRECT EFFECTS}

The direct effects of both vegetation and litter were strongly facilitative. This may be due to improved plant-water relations (DeJong \& Klinkhamer 1988; Knapp \& Seastedt 1986) or reduction of thermal stress (Franco \& Noble 1989; Valiente-Banuet et al. 1991) throughout the entire gradient. The trend towards weaker, but still facilitative, effects of litter as productivity increases is possibly due to thicker litter mats 
that may impede emergence and partially counterbalance the positive water effect. However, the lack of negative effects may indicate that light competition may not limit recruitment, even at the more productive end of this gradient where light levels at the soil surface in the control $\left(\mathrm{V}^{+} \mathrm{L}^{+}\right)$plots were depressed to levels as low as $6-15 \%$ of full sunlight. This result is at odds with the prediction that light competition with adult vegetation becomes intense at high productivity levels (Tilman 1988), in which case it would negate the possible positive effects of increased soil moisture under adult neighbours as productivity increases (Holmgren et al. 1997). Light requirements for emergence and short-term survival, the life stages addressed here, might be minimal compared to moisture requirements. Increased soil moisture might thus confer a proportionally greater benefit for seedling emergence and short-term survival if light limitation was minimal at these early life stages. Alternatively, negative effects of light competition on recruitment may only become apparent at sites that are even more productive than the ones we examined here.

The inclusion of indirect effects and interaction modifications, whether it be due to the presence of vegetation or the presence of litter (at low productivity), caused the effect of both vegetation and litter to shift to being predominately negative (compare NII to DII for both vegetation and litter). This shift suggests that, while one component of plant cover, be it live vegetation or litter, may be advantageous to ameliorate some moisture stress, the addition of a second layer may be disadvantageous. For example, the added component could limit light proportionally more than it relieves moisture stress.

Surprisingly, this shift in effect from positive to negative interactions due to the inclusion of indirect effects and interaction modifications did not occur for vegetation effects (NII-vegetation) at high productivity. This exception leads to the effect of vegetation no longer being constant along the gradient: vegetation is competitive at low levels of productivity and becomes progressively more facilitative as productivity increases. This is the opposite of the patterns predicted by Bertness \& Callaway (1994) and others and its cause is unclear. However, because facilitative effects occur in both sites of the two higher productivity community types (all prairie and fen sites), it is not is due to a community-specific abnormality. Wilson \& Tilman (1995) found a similar relationship for one of eight species: neighbours facilitated the growth of Chenopodium album under high, but not low, nitrogen conditions. Although they suggest that the presence of neighbours might decrease soil nutrient concentrations from fertilization levels that would otherwise inhibit plant growth, we doubt that such inhibition would be occurring under natural conditions. Wilson \& Tilman (1995) also found that the intensity of root competition was generally stron- ger under low nutrient conditions; if above-ground interactions remained constantly facilitative over the gradient, our result may reflect a decrease in intensity of root competition over the gradient.

\section{Conclusion}

Even after decades of experimental and conceptual work the debate concerning how competitive intensity varies with productivity remains unresolved. By quantifying interaction intensity across a range of community types, we were able to identify some general factors that may help resolve some of this conflict. First, the incorporation of plant litter effects (which represent the direct and indirect effects of past productivity) influences interaction patterns across the productivity gradient. We found that the inclusion of indirect effects of litter shifted the pattern of interaction intensity (NII-vegetation) from being constant across the entire productivity gradient to being correlated with productivity. Secondly, the aggregated population response may yield different predictions of community-level patterns than the common practice of measuring responses of a few abundant species at the individual- or population-level, because it incorporates the net response of all species populations in the community. Lastly, we must measure interaction patterns over a range of life-history stages to interpret population consequences, because these patterns may vary according to the life stage addressed. We found primarily positive interactions across the entire productivity gradient, rather than largely competitive interactions as most hypotheses predict, probably because we focused on early emergence and survival of the seedling community.

\section{Acknowledgements}

We thank Gary Fowler for statistical advice, Tony Reznicek for help selecting sites, and Marti Nash for assistance in data collection. St Joseph's Hospital, Michigan Department of Natural Resources, and Toledo Metroparks gave us permission to use their sites. We thank the plant ecology discussion group at the University of Michigan and two anonymous referees for suggestions on the manuscript. This work was supported by the ECT-Bagley Foundation.

\section{References}

Barton, A.M. (1993) Factors controlling plant distributions: drought, competition, and fire in montane pines in Arizona. Ecological Monographs, 63, 367-397.

Belcher, J.W., Keddy, P.A. \& Twolan-Strutt, L. (1995) Root and shoot competition intensity along a soil depth gradient. Journal of Ecology, 83, 673-682.

Bergelson, J. (1990) Life after death: site preemption by the remains of Poa апnиa. Ecology, 71, 2157-2165.

Berkowitz, A.R., Canham, C.D. \& Kelly, V.R. (1995) Competition vs. facilitation of tree seedling growth and sur- 
Vegetation and litter effects across gradients

(C) 1999 British Ecological Society, Journal of Ecology, 87, 436-449 vival in early successional communities. Ecology, 76, 1156-1168

Bertness, M.D. \& Callaway, R.M. (1994) Positive interactions in communities. Trends in Ecology and Evolution, 9, 191-193.

Bertness, M.D. \& Hacker, S.D. (1994) Physical stress and positive associations among marsh plants. American Naturalist, 144, 363-372.

Bertness, M.D. \& Shumway, S.W. (1993) Competition and facilitation in marsh plants. American Naturalist, 142, 718-724.

Bertness, M.D. \& Yeh, S.M. (1994) Cooperative and competitive interactions in the recruitment of marsh elders. Ecology, 75, 2416-2429.

Callaway, R.M. (1992) Effect of shrubs on recruitment of Quercus douglasii and Quercus lobata in California. Ecology, 73, 2118-2128.

Callaway, R.M. \& Walker, L.R. (1997) Competition and facilitation: a synthetic approach to interactions in plant communities. Ecology, 78, 1958-1965.

Campbell, B.D. \& Grime, J.P. (1992) An experimental test of plant strategy theory. Ecology, 73, 15-29.

Carson, W.P. \& Peterson, C.J. (1990) The role of litter in an old-field community: impact of litter quality in different seasons on plant species richness and abundance. Oecologia, 85, 8-13.

DeJong, T.J. \& Klinkhamer, P.G.L. (1988) Seedling establishment of the biennials Cirsium vulgare and Cynoglossum officinale in a sand-dune area: the importance of water for differential survival and growth. Journal of Ecology, 76, 393-402.

DeSteven, D. (1991a) Experiments on the mechanisms of tree establishment in old-field succession: seedling emergence. Ecology, 72, 1066-1075.

DeSteven, D. (1991b) Experiments on the mechanisms of tree establishment in old-field succession: seedling survival and growth. Ecology, 72, 1076-1088.

DiTommaso, A. \& Aarssen, L.W. (1991) Effect of nutrient level on competition intensity in the field for three coexisting grass species. Journal of Vegetation Science, 2, 513-522.

Facelli, J.M. \& Pickett, S.T.A. (1991) Plant litter: its dynamics and effects on plant community structure. Botanical Review, 57, 1-32.

Fenner, M. (1985) Seed Ecology. Chapman \& Hall, New York, NY.

Foster, B.L. (1999) Establishment, competition, and the distribution of native species among Michigan old-fields. Journal of Ecology, 87, 476-489.

Foster, B.L. \& Gross, K.L. (1997) Partitioning the effects of plant biomass and litter on Andropogon gerardii in oldfield vegetation. Ecology, 78, 2091-2104.

Fowler, N.L. (1986) Microsite requirements for germination and establishment of three grass species. American Midland Naturalist, 115, 131-145.

Fowler, N.L. (1988) What is a safe site? Neighbor, litter, germination date, and patch effects. Ecology, 69, 947961.

Franco, A.C. \& Noble, P.S. (1989) Effect of nurse plants on the microhabitat and growth of cacti. Journal of Ecology, 77, 870-886.

Goldberg, D.E. (1987a) Neighborhood competition in an old-field plant community. Ecology, 68, 1211-1223.

Goldberg, D.E. (1987b) Seedling colonization of experimental gaps in two old-field communities. Bulletin of the Torrey Botanical Club, 114, 139-148.

Goldberg, D.E., Rajaniemi, T., Gurevitch, J. \& StewartOaten, A. (1999) Empirical approaches to quantifying interaction intensity: competition and facilitation along productivity gradients. Ecology, in press.

Greenlee, J. \& Callaway, R.M. (1996) Effects of abiotic stress on the relative importance of interference and facilitation. American Naturalist, 148, 386-396.

Grime, J.P. (1979) Plant Strategies and Vegetation Processes. John Wiley, London, UK.

Grime, J.P. \& Jarvis, B.C. (1975) Shade avoidance and shade tolerance in flowering plants. II. Effects of light on the germination of species of contrasted ecology. Light as an Ecological Factor, Vol. II (eds R. Bainbridge, G.C. Evans \& O. Rackham), pp. 525-532. Blackwell, London. UK.

Grubb, P.J. (1985) Plant population and vegetation in relation to habitat disturbance and competition: problems of generalizations. The Population Structure of Vegetation (ed. J. White), pp. 595-621. Dr W. Junk, The Hague, the Netherlands.

Grubb, P.J., Kelly, D. \& Mitchley, J. (1982) The control of relative abundance in communities of herbaceous plants. The Plant Community as a Working Mechanisms (ed. E.I. Newman), pp. 79-97. Special publication No. 1 of the British Ecological Society, Blackwell Scientific Publications, Oxford.

Gurevitch, J. (1986) Competition and the local distribution of the grass Stipa neomexicana. Ecology, 67, 46-57.

Harper, J.L. (1977) Population Biology of Plants. Academic Press, New York, NY.

Holmgren, M., Scheffer, M. \& Huston, M.A. (1997) The interplay of facilitation and competition in plant communities. Ecology, 78, 1966-1975.

Huston, M. (1979) A general hypothesis of species diversity. American Naturalist, 113, 81-101.

Kadmon, R. (1995) Plant competition along soil moisture gradients: a field experiment with the desert annual Stipa capensis. Journal of Ecology, 83, 253-262.

Keddy, P.A. (1989) Competition. Chapman \& Hall, London, UK.

Kellman, M. \& Kading, M. (1992) Facilitation of tree seedling establishment in a sand dune succession. Journal of Vegetation Science, 3, 679-688.

Knapp, A.K. \& Seastedt, T.R. (1986) Detritus accumulation limits productivity of tallgrass prairie. Bioscience, $\mathbf{6 8}$, 622-668.

McAuliffe, J.R. (1984) Sahuaro-nurse tree associations in the Sonoran Desert: competitive effects on saguaros. Oecologia, 64, 319-321.

Markham, J.H. \& Chanway, C.P. (1996) Measuring plant neighbor effects. Functional Ecology, 10, 548-549.

Moore, D.R.J. \& Keddy, P.A. (1989) The relationship between species richness and standing crop in wetlands: the importance of wetlands. Vegetatio, 79, 99-106.

Newman, E.I. (1973) Competition and diversity in herbaceous vegetation. Nature, 244, 310.

Peckarsky, B.L., Cooper, S.D. \& McIntosh, A.R. (1997) Extrapolating from individual behavior to populations and communities in streams. Journal of the North American Benthological Society, 16, 375-390.

Sokal, R.R. \& Rohlf, F.J. (1995) Biometry: the Principles and Practice of Statistics in Biological Research. W.H. Freeman, New York, NY.

Thompson, K. \& Grime, J.P. (1988) Competition reconsidered - a reply to Tilman. Functional Ecology, 2, 114 116.

Tilman, D. (1987) Secondary succession and the pattern of plant dominance along experimental nitrogen gradients. Ecological Monographs, 57, 189-214.

Tilman, D. (1988) Plant Strategies and the Dynamics and Structure of Plant Communities. Princeton University Press, Princeton, NJ.

Tilman, D. (1989) Competition, nutrient reduction and the competitive neighborhood of a bunchgrass. Functional Ecology, 3, 215-219.

Turkington, R., Klein, E. \& Chanway, C.P. (1993) Inter- 
active effects of nutrients and disturbance: an experimental test of plant strategy theory. Ecology, 74, 863878.

Twolan-Strutt, L. \& Keddy, P.A. (1996) Above and belowground competition intensity in two contrasting wetland plant communities. Ecology, 77, 259-270.

Valiente-Banuet, A., Vite, F. \& Zavala-Hurtado, J.A. (1991) Interaction between the cactus Neobuxbaumia tetetzo and the nurse shrub Mimosa luisana. Journal of Vegetation Science, 2, 11-14.

Van der Valk, A.G. (1986) The impact of litter and annual plants on recruitment from the seed bank of a lacustrine wetland. Aquatic Botany, 24, 13-26.

Wilson, S.D. (1993) Belowground competition in forest and prairie. Oikos, 68, 146-150.

Wilson, S.D. (1994) Initial size and the competitive response of two levels of soil nitrogen: a field experiment. Canadian Journal of Botany, 72, 1349-1354.

Wilson, S.D. \& Keddy, P.A. (1986) Measuring diffuse competition along an environmental gradient: results from a shoreline community. American Naturalist, 127, 862869.

Wilson, S.D. \& Shay, J.M. (1990) Competition, fire, and nutrients in a mixed-grass prairie. Ecology, 71, 1959 1967.

Wilson, S.D. \& Tilman, D. (1991) Components of plant competition along an experimental gradient of nitrogen availability. Ecology, 72, 1050-1065.

Wilson, S.D. \& Tilman, D. (1995) Competitive responses of eight old-field plant species in four environments. Ecology, 76, 1169-1180.

Wisheu, I.C. \& Keddy, P.A. (1992) Competition and centrifugal organization of plant communities: theory and tests. Journal of Vegetation Science, 3, 147-156.

Wootton, J.T. (1993) Indirect effects and habitat use in an intertidal community: interaction chains and interaction modification. American Naturalist, 141, 71-89.

Received 6 March 1998

revision accepted 3 November 1998
(C) 1999 British

Ecological Society, Journal of Ecology, 87, 436- 449 